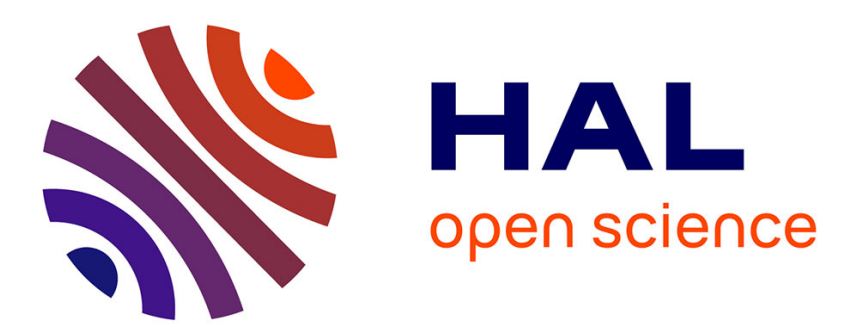

\title{
Effects of the composition of hot-melt adhesives on their bulk and interfacial properties
}

\author{
M. Nardin, M. Brogly, J. Schultz
}

\section{To cite this version:}

M. Nardin, M. Brogly, J. Schultz. Effects of the composition of hot-melt adhesives on their bulk and interfacial properties. Journal de Physique IV Proceedings, 1993, 03 (C7), pp.C7-1505-C7-1510. 10.1051/jp4:19937235 . jpa-00251872

\section{HAL Id: jpa-00251872 https://hal.science/jpa-00251872}

Submitted on 1 Jan 1993

HAL is a multi-disciplinary open access archive for the deposit and dissemination of scientific research documents, whether they are published or not. The documents may come from teaching and research institutions in France or abroad, or from public or private research centers.
L'archive ouverte pluridisciplinaire HAL, est destinée au dépôt et à la diffusion de documents scientifiques de niveau recherche, publiés ou non, émanant des établissements d'enseignement et de recherche français ou étrangers, des laboratoires publics ou privés. 


\title{
Effects of the composition of hot-melt adhesives on their bulk and interfacial properties
}

\author{
M. NARDIN, M. BROGLY and J. SCHULTZ
}

Centre de Recherches sur la Physico-Chimie des Surfaces Solides, CNRS, 24 avenue du Président Kennedy, 68200 Mulhouse, France

\begin{abstract}
Specific interactions in binary blends, models of hot-melt adhesives, of ethylenevinylacetate copolymer (EVA) with different terpene-phenol low molecular weight tackifying resins (TPR) are first investigated by means of Fourier transform infrared spectroscopy (FTIR) as a function of the composition of the blend. Molecular electron donor-acceptor (or "acid-base" according to Lewis' concept) complexes are clearly evidenced between TPR hydroxyl and EVA carbonyl groups. Quantitative data on the fraction of acid-base bonded carbonyl groups and the enthalpy of pair formation are then obtained. Secondly, the analysis of the interface between the blends and basic (aluminium) or acidic (glass) substrates by FTIR allows us to show the establishment and to quantify the strength of acid-base interfacial interactions in both cases. Finally, the comparison between the interfacial and bulk properties data and adhesive strength measurements (peel energy) leads to the estimation of fundamental parameters of adhesion science, in particular the acid-base component of the energy of adhesion and the number of acidbase interactions per unit interfacial area.
\end{abstract}

\section{Introduction}

Blending as a route for improving specific material performance is nowadays well established. The use of hot-melt adhesives as bonding and sealing agents requires different properties of the blends such as a low viscosity allowing fast processing in the melted state as well as a high level of adhesion and a high loss modulus in the working conditions. These properties can be tailored essentially by blending and, therefore, miscibility in the blend is of fundamental importance. Due to the lack of a large mixing entropy, strong specific interactions are then required to achieve thermodynamic miscibility. Such interactions established between electron donor and electron acceptor groups (or acid-base groups in terms of Lewis' approach) can be easily evidenced by Fourier transform infrared spectroscopy (FTIR), since they lead to frequency shifts of the absorption bands of these groups. In the present study, binary blends, models of hot-melt adhesives, of ethylene-vinylacetate copolymer (EVA) with different terpene-phenol low molecular weight tackifying resins (TPR) are analysed. A first part is devoted to the formation of acid-base complexes in the bulk as a function of the composition of the blend and the degree of functionality of the components, by measuring the relative proportion of free and acid-base bonded electron donor groups. The magnitude of the thermodynamic miscibility is therefore discussed. In a second part, the establishment of acid-base interactions at the interface between those blends and two different types of substrates, a basic (aluminium) and an acidic (glass) substrates, are analysed by means of infrared reflection-absorption spectrometry (IRRAS). Finally, a tentative correlation between, on the one hand, the interfacial and bulk spectroscopic data and, on the other hand, adhesive strength measurements (peel energy) is proposed. 


\section{Experimental}

The EVA copolymer (Fig. 1a), supplied by Elf-Atochem (France), had a vinylacetate content (VA) of $28 \%$ by weight and an average molecular weight $M_{w}$ of $27,000 \mathrm{~g} / \mathrm{mol}$. Three terpene-phenol resins TPR 1 , 2 and 3 with different degrees of functionality $d(O H)$ were used (Fig. $1 \mathrm{~b}$ ), this degree $\mathrm{d}(\mathrm{OH})$ being defined as the average number of hydroxyl groups per molecule of resin. The $\mathrm{d}(\mathrm{OH})$ values were equal to $0.7,1.1$ and 1.4 hydroxyl groups per molecule, whereas the average molecular weights $M_{w}$ were 840,670 and $570 \mathrm{~g} / \mathrm{mol}$ for TPR 1,2 and 3 respectively. The thermal properties of all these products were studied by differential scanning calorimetry (DSC, Mettler TA3000) at a $10^{\circ} \mathrm{C} / \mathrm{min}$ heating rate.
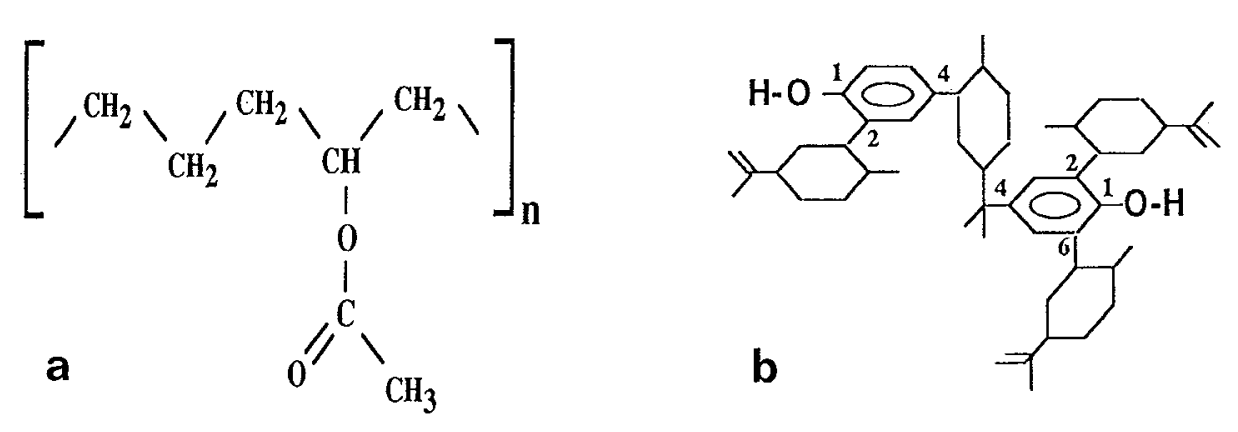

Figure 1: Chemical formula of (a) EVA copolymer and (b) terpene-phenol resin with $d(O H)=2$.

Samples, with EVA content ranging from 30 to $70 \%$ by weight, were prepared by mixing TPR and EVA under nitrogen at a constant temperature. Thin films for FTIR analysis were obtained by moulding under 1.5 MPa pressure at $150^{\circ} \mathrm{C}$ and, then, examined in attenuated total reflection mode (ATR).

Two kinds of substrates were used : aluminium (A4, 99.4\% of purity) and glass (optical quality). In order to analyse the interfacial interactions between these substrates and TPR, EVA or blends, the following procedure was used. A thick film $(\approx 50 \mu \mathrm{m})$ of polymers was first moulded onto the substrates, then gradually dissolved by dipping into chloroform until its thickness reaches about $30 \mathrm{~nm}$ (determined by weight measurements) leading to the best conditions for FTIR analysis. The interfacial region was therefore studied by IRRAS technique at an angle of incidence of $82^{\circ}$ for aluminium and $60^{\circ}$ for glass substrates. All the infrared spectra (ATR and IRRAS) were recorded on a Bruker IFS-66 spectrometer at a resolution of $2 \mathrm{~cm}^{-1}$ by averaging 100 scans.

Finally, the peel energy $G$, in air or in presence of ethanol, between elastic aluminium tapes $(100 \mu \mathrm{m}$ thick) and the various EVA/TPR blends ( $100 \mu \mathrm{m}$ thick) moulded on thick aluminium sheets was measured by $180^{\circ}$ peeling experiments at different peeling rates ranging from 0.5 to $500 \mathrm{~mm} / \mathrm{min}$. In these conditions, $G$ is equal to $2 F / b$, where $F$ is the peeling force and $b$ the width of the sample.

\section{Results and discussion}

\subsection{Bulk properties}

First, the carbonyl stretching band in EVA/TPR blends appears to have two contributions, attributed respectively to the free carbonyl groups at $1736 \mathrm{~cm}^{-1}$, as in neat EVA polymer [1,2], and to the acid-base bonded carbonyl groups [3] at about $1707 \mathrm{~cm}^{-1}$. Figure 2 gives the evolution of the splitted carbonyl stretching absorption bands as a function of blend ratio for TPR1. The acid-base bonded carbonyl band first appears as a poorly resolved shoulder at low TPR content and then becomes highly resolved as the TPR content increases. These results clearly indicate that acid-base interactions in the blend fit a stoichiometric law of mixing, allowing us to calculate the fraction of acid-base bonded carbonyl groups, 
$f_{(C=O)}^{A B}$, as described in a previous study $[1,2]$. For a given composition of the blend, this fraction increases with the degree of functionality of the TPR resin. Secondly, in the $3800-3200 \mathrm{~cm}^{-1}$ region, a complex hydroxyl group vibration absorption band is present revealing also the existence of acid-base interactions between EVA carbonyl groups and TPR hydroxyl groups. Mean peak positions are 3460 and $3400 \mathrm{~cm}^{-1}$, different from those of pure TPR resins, indicating a non-equivalence of interacting sites due to the two types of phenol substitution (1-2-4 and 1-2-4-6 as shown in Fig. 1b).

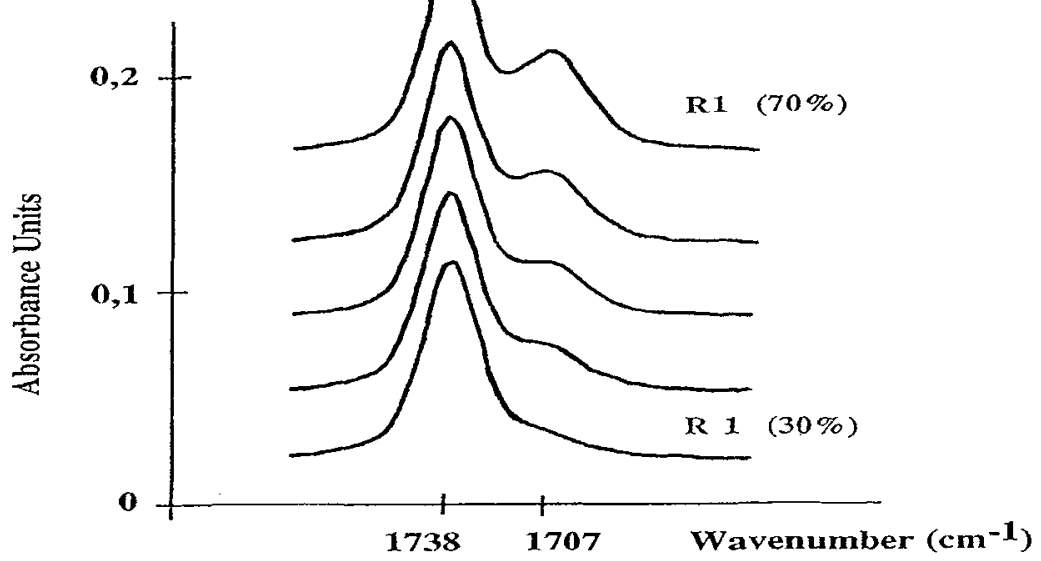

Figure 2: Free and acid-base bonded carbonyl absorption bands as a function of blend composition.

Finally, the main consequence of the existence of such acid-base complexes is that EVA and TPR resins are perfectly miscible whatever the composition of the blend, as confirmed by DSC experiments where a unique glass transition temperature is recordered. However, when the content of EVA exceeds about 40 to $50 \%$ by weight, a crystalline phase (ethylene chains enriched phase) appears as revealed by DSC $[1,2]$.

\subsection{Interactions at blends/substrates interfaces}

The interactions established between neat EVA or TPR resins and aluminium or glass substrates are first investigated. IRRAS analysis of EVA/aluminium systems clearly shows the presence of a peak at $1724 \mathrm{~cm}^{-1}$ corresponding to carbonyl groups which interact with aluminol groups at the oxidized aluminium surface (Fig. 3a), according to n. $\sigma^{*}$ type acid-base interactions.
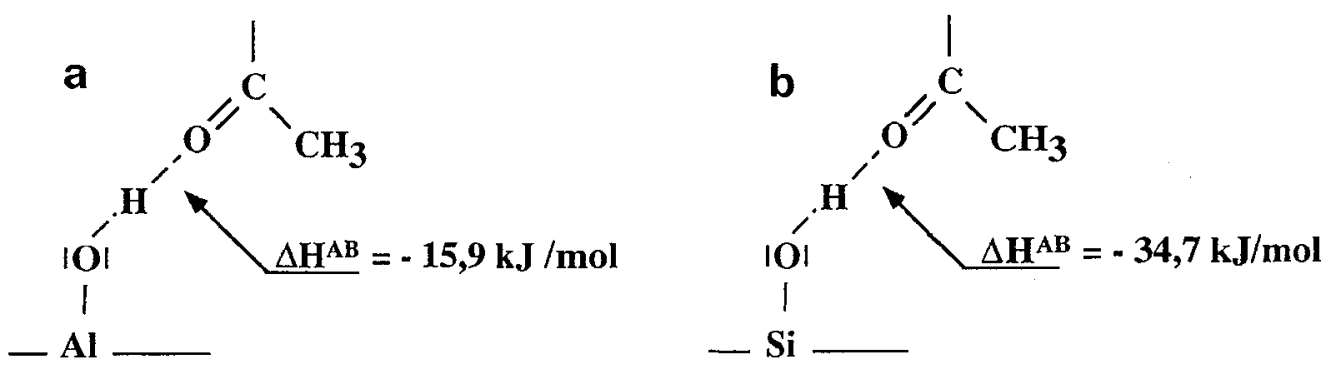

Figure 3 : Acid-base interactions (n. $\sigma^{*}$ type) at aluminium (a) or glass (b) - EVA interfaces. 
In agreement with Fowkes [4], who has proposed that the variation of enthalpy $-\Delta H^{A B}$ for the establishment of such interactions is directly proportional to the frequency shift of the absorption band, an estimated value for $-\Delta \mathrm{HAB}$ of about $16 \mathrm{~kJ} / \mathrm{mol}$ is found. For a more acidic substrate, such as glass, the same type of interactions between carbonyl groups and silanol function is established (Fig. 3b), but now $\Delta \mathrm{H}^{\mathrm{AB}}$ value is greatly increased and reaches about $35 \mathrm{~kJ} / \mathrm{mol}$.

In the case of TPR/aluminium systems, a new contribution for the absorption band of the phenolic ring at $1515 \mathrm{~cm}^{-1}$, corresponding to the interactions between $\pi$-electrons with hydroxyl function (n. $\pi^{*}$ type of acid-base interactions), as well as a new peak appearing at $3240 \mathrm{~cm}^{-1}$ clearly show that acid-base interfacial interactions are directly established between the phenolic ring of TPR resins and the oxygen atom of the aluminol groups present on the aluminium surface (Fig. 4). According to Murphy and Rao [5], this leads to an estimated value of $-\Delta \mathrm{H}^{\mathrm{AB}}$ close to $31 \mathrm{~kJ} / \mathrm{mol}$, i.e. twice this for carbonyl-aluminol groups interactions.

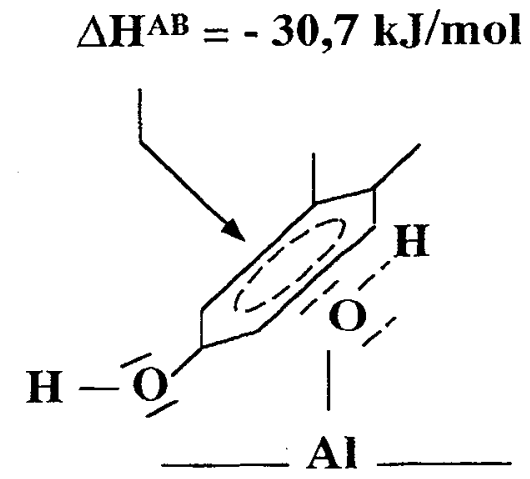

Figure 4: Acid-base interactions (n. $\pi^{*}$ type) at aluminium - TPR interfaces.

If now EVA/TPR blends are put into contact with both substrates and taking into account previous values of the different enthalpies of interactions, preferential interactions between TPR and aluminium surface and, on the contrary, between EVA and glass surface are expected at the respective interfaces. Effectively, such interactions are clearly evidenced experimentally, by the presence of the band at $1515 \mathrm{~cm}^{-1}$ (phenolic ring/AlOH interaction) in the former case and the band at $1724 \mathrm{~cm}^{-1}(\mathrm{C}=\mathrm{O} / \mathrm{SiOH}$ interaction) in the latter case. In particular, values of $-\Delta \mathrm{H}^{\mathrm{AB}}$ of about 30 and $35 \mathrm{~kJ} / \mathrm{mol}$ are respectively obtained in good agreement with previous results (see Figs 4 and $3 b$ ).

\subsection{Peel energy}

According to the rheological model of adhesion, originally proposed by Gent and Schultz [6], the peel energy $G$ is proportional to the reversible energy of adhesion W (Dupré's energy relative to physical interactions - Van der Waals- only) established at the interface and to the viscoelastic dissipation function of the adhesive $\phi$, which depends on the peeling rate $v$ and the temperature $T$, i.e. : $G=W . \phi(v, T)$.

When interfacial failure occurs, in presence of a liquid [7] such as ethanol, all the physical interactions between adhesive and substrate are now avoided and the new peel energy $G_{1}$ is decreased and given by : $G_{1}=W_{1} . \phi(v, T)$, where $W_{1}$ takes into account the interfacial energies at the respective interfaces of the system adhesive/ethanol/substrate. As an example, Figure 5 shows the results of peel experiments in the case of EVA-TPR1 (50\%) blend/aluminium. Therefore, considering that the bulk viscoelastic properties of the adhesive remain unchanged, the ratio $G_{1} / G$ must be equal to $W_{1} / W$, which is easily calculated, since experimental values of $W$ and $W_{1}$ can be obtained knowing the surface energy of both materials in contact [1]. However, for all the systems studied, it appears that the experimental values of $G_{/} / G$ are lower than the theoretical ones, i.e. $\mathrm{W}_{1} / \mathrm{W}$. This indicates that strong interactions, such as covalent bonds or acid-base interactions, which are not sensitive to the presence of ethanol, are established at blend/substrate interfaces. On the one hand, no covalent bonds have been evidenced at the interface by FTIR spectroscopy. On the other hand, acid-base interactions of $n . \pi^{*}$ type between phenolic ring and aluminol are not destroyed by 
ethanol, since the formation of acid-base pairs between ethanol and the adhesive or the substrate corresponds to lower absolute values of $\triangle \mathrm{H}^{\mathrm{AB}}[8]$.

Therefore, the discrepancy between experimental results and theoretical predictions can be essentially attributed to acid-base interactions established at blends/substrates interfaces and, considering that the reversible work of adhesion is the sum of two components, $\mathrm{W}^{\mathrm{D}}$ and $\mathrm{W}^{\mathrm{AB}}$, corresponding respectively to Van der Waals and acid-base interactions, the term $W^{A B}$ can be estimated from the experimental value of $\mathrm{G}_{1} / \mathrm{G}$.

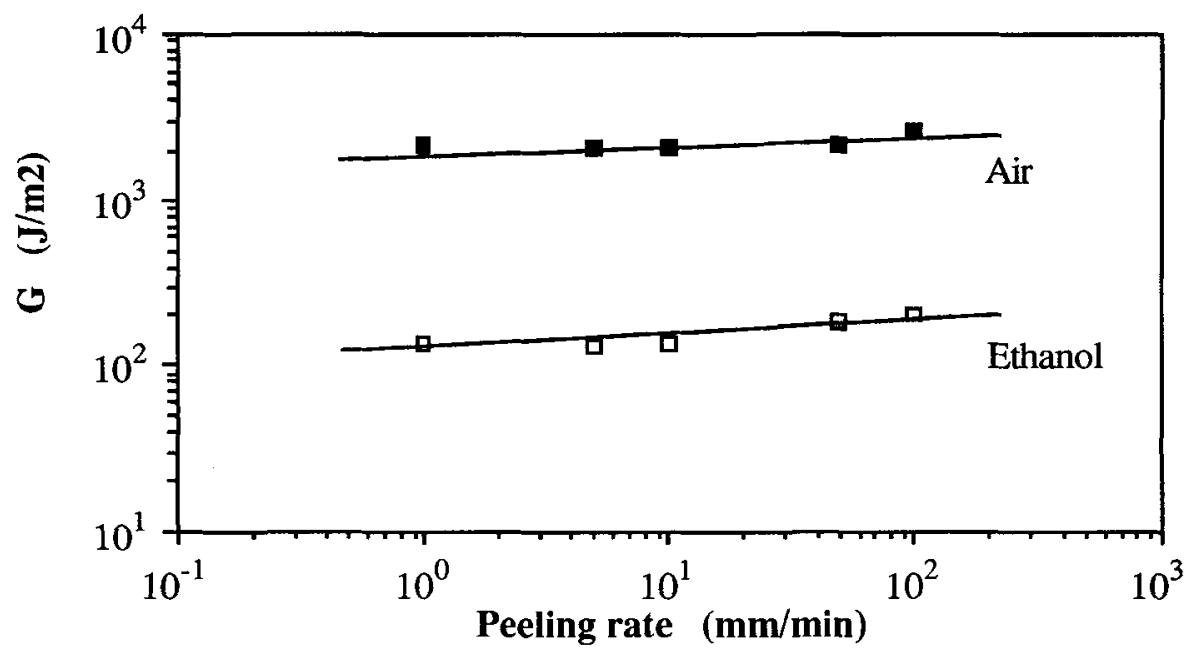

Figure 5 : Peel energy in air and in presence of ethanol for EVA-TPR 1 (50\%) blendlaluminium system versus peeling rate.

Moreover, Fowkes and Mostafa [9] have proposed for $\mathrm{WAB}^{\mathrm{B}}$ the following expression : $\mathrm{WAB}=\mathrm{f} \cdot \mathrm{n}^{\mathrm{AB}} \cdot\left(-\Delta \mathrm{H}^{\mathrm{AB}}\right)$, where $\mathrm{n}^{\mathrm{AB}}$ is the number of acid-base pairs per unit interfacial area and $\mathrm{f}$ is a correcting factor to transform enthalpy values into free energy values and taken equal to unity. Since the value of $-\triangle H^{A B}$ has been previously determined by FTIR $\left(-\Delta H^{A B}=30 \mathrm{~kJ} / \mathrm{mol}\right.$ for blends/aluminium systems), an estimation of $\mathrm{n}^{\mathrm{AB}}$ can be then proposed. Typical values of $\mathrm{W}^{\mathrm{AB}}$ and $\mathrm{n}^{\mathrm{AB}}$ for EVA-TPR 1,2 and 3 (at $50 \%$ by weight) in contact with aluminium are gathered in Table 1.

Table 1 : Acid-base component $W^{A B}$ of the work of adhesion and number of acid-base pairs per unit interfacial area $n^{A B}$ for different EVA-TPR (50\%) blends/aluminium interfaces.

\begin{tabular}{|c|c|c|}
\hline $\begin{array}{c}\text { Type of TPR in the } \\
\text { blend }\end{array}$ & $\begin{array}{c}\text { WAB } \\
\left(\mathrm{mJ} / \mathrm{m}^{2}\right)\end{array}$ & $\begin{array}{c}\mathbf{n} \mathbf{A B} \\
\left(\mu \mathrm{mol} / \mathrm{m}^{2}\right)\end{array}$ \\
\hline 1 & 13.5 & 0.5 \\
2 & 30 & 1 \\
3 & 118 & 4 \\
\hline
\end{tabular}


These values of $\mathrm{W}^{\mathrm{AB}}$ and $\mathrm{n}^{\mathrm{AB}}$ are in good agreement with those available in the literature for other systems [8]. It appears in particular that the number of acid-base interactions $n^{A B}$ at the interface increases with the functionality $\mathrm{d}(\mathrm{OH})$ of the resin and, then, with the density of acid-base complexes n. $\sigma^{*}$ existing in the bulk of the blend and represented, to a first approximation, by the fraction of acid-base bonded carbonyl groups $f_{(C=O)}^{A B}$. Therefore, it is possible to conclude that the increase of the volume density of such complexes in the bulk leads to an increase of the probability of presence of these complexes at the interface and then of the number of interactions effectively established between the blend and the substrate.

\section{Conclusion}

In this study, by FTIR spectroscopy, it is first shown that acid-base interactions are established between carbonyl groups of EVA and hydroxyl functions of TPR resin in binary blends, models of hotmelt adhesives. These interactions are responsible for the thermodynamic miscibility between both constituents in the amorphous phase of the blends. Secondly, acid-base interactions are also evidenced at the interface between these blends and aluminium or glass substrates. In the former case, $n . \pi^{*}$ complexes between phenolic rings of TPR and aluminol groups are preferentially formed, whereas, in the latter case, n. $\sigma^{*}$ interactions between carbonyl groups of EVA and silanol functions are favoured. In each case, the variation of enthalpy corresponding to the formation of acid-base pairs is determined by means of FTIR analysis. Finally, the adhesive strength (peel energy) of blend/aluminium interfaces, measured in air and in liquid environment, allows us, by taking into account this variation of enthalpy, to calculate fundamental parameters of adhesion, in particular, the acid-base component of the work of adhesion as well as the interfacial density of acid-base pairs. Moreover, it is shown that a direct relationship exists between the bulk density of acid-base complexes in the blend and the number of acid-base interactions effectively established at the interface.

\section{Acknowledgements}

Thanks are due to the ELF-ATOCHEM Company and particularly to Drs. R. Panaras, M. Bourrel and J. Komornicki for financial support and helpful discussions.

\section{References}

[1] Brogly M., PhD Thesis, Université de Haute-Alsace, Mulhouse, France, (1993).

[2] Brogly M., Nardin M. and Schultz J., Macromolecules, submitted for publication.

[3] Moskala E.J., Runt J.P. and Coleman M.M., in "Multicomponents Polymer Materials", Adv. in Chemistry, Ser. 211, Paul \& Sperlings Eds, ACS, Washington DC, (1986).

[4] Fowkes F.M., Tischler D.O., Wolfe J.A., Lannigan L.A., Ademu-John C.M. and Halliwell M.J., J.Polym. Sci.-Polym. Chem. Ed. 22 (1984) 547.

[5] Murphy A.S.M. and Rao C.N.R., Appl. Spectr. Rev. 2 (1968) 69.

[6] Gent A.N. and Schultz J., J. Adhesion 3 (1972) 28.

[7] Schultz J., Tsutsumi K. and Donnet J.B., J. Colloid Interface Sci. 59 (1977) 272.

[8] Fowkes F.M., J. Adhesion Sci. Technol. 1 (1987) 7.

[9] Fowkes F.M. and Mostafa M.A., Ind. Eng. Chem. Prod. Res. Dev. 17 (1978) 3. 